\title{
Can we prevent accidental injury to adolescents? A systematic review of the evidence
}

\author{
James Munro, Pat Coleman, Jon Nicholl, Rosemary Harper, Gerry Kent, Deborah Wild
}

\begin{abstract}
Objectives-As part of the Department of Health strategy The Health of the Nation, a systematic review of published and unpublished literature relating to the effectiveness of interventions in reducing accidental injury in the population aged 15-24 years was carried out.

Methods-The literature was reviewed under the standard setting headings of road, work, home, and sports and leisure, and graded for quality of evidence and strength of recommendation using a scale published in the UK national epidemiologically based needs assessment programme.
\end{abstract}

Results-The most effective measures appear to be legislative and regulatory controls in road, sport, and workplace settings. Environmental engineering measures on the road and in sports have relatively low implementation costs and result in fewer injuries at all ages. There is little evidence that purely educational measures reduced injuries in the short term. Community based approaches may be effective in all age groups, and incentives to encourage safer behaviour hold promise but require further evaluation. The potential of multifactorial approaches seems greater than narrowly based linear approaches.

Conclusions-Few interventions to reduce injury in adolescents have been rigorously evaluated using good quality randomised controlled trials, and where such evidence is available, fewer have been shown to be definitely worthwhile. Many studies relied on surrogate measures rather than actual injury rates, and substantial issues relating to the efficacy or implementation of preventive measures in adolescent and young adult populations remain unresolved.

(Injury Prevention 1995; 1: 249-255)

Keywords: adolescents, effectiveness, systematic review.

While injury prevention in children and the elderly has received considerable attention from both researchers and policymakers, adolescents and young adults (those aged
15-24 years) have been relatively neglected. This is surprising, given the popular perception of adolescents as uninhibited and deliberate risk takers. In fact, popular perception has much to be said for it, and the epidemiology of accidents in this age group gives no cause for complacency. For example, rates of death and serious injury among car and motorcycle users increase rapidly after the age of 14, reaching a peak in the early $20 \mathrm{~s}$. By contrast, rates among pedestrians and bicycle users fall gradually after the age of 14 . Over $80 \%$ of accidental deaths in teenagers (aged $15-19$ years) are due to road accidents. ${ }^{1}$ Nor is the problem confined to the roads. From 1982 to 1993 approximately 190 fatal injuries occurred annually in sporting and leisure activities, and young males aged 15-24 accounted for $32 \%$ of these. ${ }^{2}$

As a part of the UK's The Health of the Nation strategy, ${ }^{3}$ we undertook a systematic review of the evidence on the effectiveness of interventions to prevent injuries in this age group. Our objectives were to identify those interventions that have been shown to be effective in well designed studies, so that their widespread introduction might be encouraged, and to highlight those areas where evidence is weak or non-existent, so that priorities might be set for further research.

\section{Methods}

A comprehensive search of the published and unpublished English language literature since 1966 was undertaken. The search strategy included online and CD-ROM databases, as well as approaches to authors, government departments, and voluntary agencies with particular interests in accident prevention in young people.*

Studies of interventions aimed at reducing injuries in 15-24 year olds, or with particular relevance to this age group, were explicitly graded according to the scheme used in the UK epidemiologically based needs assessment programme. ${ }^{4}$ Ultimately, the important outcomes that an intervention must achieve are a reduction in accident rates, in the severity of injuries that result from an accident, or both. Many studies in accident research are field trials, laboratory tests, or crash tests, which indicate

*Details of the search strategy are available on request. 
what ought to happen as a result of the intervention. Evidence on actual outcomes can only come from population based studies of an intervention in everyday use. We therefore regarded the strength of recommendations that could be made on the basis of the former types of study as inherently weaker than those based on the latter.

\section{Road users}

\section{BICYCLISTS AND MOTORCYCLISTS}

Helmet use

A large body of evidence from America, Australia, and the UK suggests that both incidence and severity of head injury are lower in cyclists wearing helmets at the time of an accident, compared with those who are not. ${ }^{5-14}$ This effect increases with the robustness of the helmet design. ${ }^{15}$

Existing evidence comes from both cohort and case-control studies that attempt to control for possible confounding factors, the most important of which is severity. Only one study found evidence suggesting that severity may be less in helmet wearers than non-wearers. ${ }^{11}$ In that study, helmets wearers suffered both less severe head injury and less severe non-head injury than other cyclists, raising the possibility that helmet wearing is a marker of a 'safer cyclist' or an 'emergency service user' rather than (or as well as) providing protection in its own right. Studies of helmet effectiveness may suffer from a number of biases which are difficult to eliminate. ${ }^{16}$

Legislation making cycle helmet use mandatory has been effective in increasing the proportion of cyclist who wear a helmet, in decreasing numbers of head injured cyclists, and in decreasing the number of bicycle accidents in any kind, ${ }^{17-21}$ although the extent to which reduced injuries are related to a fall in bicycle use is unclear. A recent review has examined the effectiveness of educational and legislative strategies to promote bicycle helmet use. $^{22}$

Similarly, legislation on motorcycle helmet use is followed by a reduction in motorcycle fatalities by about $30 \%$, and the experience of some US states shows that repeal is followed by an increase in fatalities of $25-40 \% .^{23-27}$

\section{Other measures}

Evidence from field trials has shown that reflective clothing may be effective in increasing bicyclist conspicuity under test conditions.$^{28}$ Both cycle spacers and reflective jackets proved effective in discouraging close overtaking in normal traffic. However, there are no studies of the effect on injury rates.

Similarly, evidence from field trials suggests that reflective clothing, daytime running lights, and daytime headlight use increase motorcycle conspicuity. ${ }^{29} 30$ Unfortunately, comparative studies do not show any effect of daytime headlight use on injury rates or motorcycle fatalities in US states where such use is mandatory. ${ }^{31} 32$

The majority of studies examining the effectiveness of training in reducing motorcycle injury rates have found no effect. ${ }^{33-38}$ Although a recent study did find an effect in reducing risk, the size of this effect diminished after two years. ${ }^{39}$

A number of studies have found that trained riders make greater use of protective clothing. ${ }^{34}$ It is certainly possible that the results of these studies are attributable to selection bias rather than the effects of the training itself.

Given the evidence available, only two interventions emerge as being clearly effective in reducing death or injury due to bicycle or motorcycle accidents. The first is the use of cycle or motorcycle helmets. The second is almost any legislative intervention imposing new constraints on cycle or motorcycle riders. The effectiveness of individual components of legislation is often uncertain, and injury and fatality numbers may fall simply because the legislation produces a decline in bicycle or motorcycle use. Evidence on other potential interventions is either contradictory or shows small or non-existent effects on injury rates.

\section{OTHER ROAD USERS \\ Education}

While both experience, which cannot be 'taught', and age effects, which might be modifiable by education, affect injury rates, ${ }^{40}$ the limited evidence on educational and training interventions indicates that enhanced driver education courses have little or no effect. Reviews in the early literature on the effectiveness of driver education courses ${ }^{41-43}$ concur with this finding and with later reviews. ${ }^{44} \mathrm{~A}$ review of 'methodologically sound' studies of post-licence defensive driving courses $^{45}$ and a systematic review of 19 methodologically sound studies of driver improvement programs ${ }^{46}$ also found no benefits.

Programmes based solely on the provision of information have also been disappointing. School based programmes, rehabilitation for drink-drivers, and education on the effects of catastrophic injury have demonstrated changes in self reported behaviour, attitudes and knowledge, ${ }^{47-50}$ but not in objective behavioural change. ${ }^{48}$ Studies into the effects of media campaigns on seat belt use have also produced conflicting conclusions. ${ }^{5152}$ This does not necessarily mean that giving information is irrelevant. It may be more helpful to see knowledge as a necessary condition for behavioural change, but insufficient in itself.

Behaviour may be modifiable more directly by providing reinforcement or incentives for changes in the desired direction. Although studies exist reporting positive associations with rewards for safer behaviour in children, ${ }^{5354}$ there is surprisingly little evidence evaluating such inducements in adolescents. However, two studies describing the effects of reductions in bus fares may be especially relevant to young people. Travel by bus or coach is known to be associated with a far smaller risk of injury than travel by typical alternatives for young people, such as pedal cycles and mopeds. ${ }^{55}$ Nicholl et al showed that 
gradual reductions in bus fares resulted in an increase in bus travel, rather than alteration in the mode of travel, ${ }^{56}$ while Allsop showed that sudden changes in the relative cost of bus travel brought about a change in the mode of travel..$^{57}$

Adolescents tend to see themselves as having a high degree of control over the consequences of their behaviour and as unlikely to suffer the consequence of risky behaviour, ${ }^{5859}$ including car driving at higher than legal speeds or under the influence of alcohol. ${ }^{6061}$ They may have unrealistic beliefs about their skills and may deliberately choose to take risks. ${ }^{62-64}$

In view of this, multifactorial programmes that seek to alter several aspects of adolescents' beliefs, skills, and values may be more effective than those that seek to alter only one aspect. Such programmes, which take a variety of approaches, for example role play (in which participants practice countering peer pressures), encouraging alternative behaviour (using alternative means of transport when drinking), and the development of social norms against drinking and driving, may change knowledge, attitudes, and self reported behaviour. ${ }^{6566}$

However, programmes that unintentionally enable adolescents to drive at a younger age than they otherwise would may have a negative effect. ${ }^{67}$ This suggests that raising the legal driving age may be effective.

\section{Legislation}

Studies of legislative interventions reveal numerous possibilities, such as drink-driving legislation, or imposing night time driving curfews on young drivers.

Evidence on the effect of raising the minimum legal driving age comes from cross sectional studies in the US where different states have different minimum ages, ${ }^{68-71}$ and consistently shows that age itself, as well as experience, plays a key part in determining accident rates. The studies reviewed universally failed to assess the impact of altering the minimum licensing age on injuries to other road users. As such a change may result in an increase in young motorcyclists, pedal cyclists, and pedestrians, the net effect may be less than has been shown for drivers alone. When the minimum drinking age is raised above 18 years, all the studies identified report a decrease in young driver (and passenger) fatalities. ${ }^{72-77}$

By contrast, evidence for the effectiveness of stricter enforcement of drinking and driving laws, or even random breath testing, is less clear cut, and it is difficult to assess the degree of benefit such measures could provide. ${ }^{78-80}$

A number of states in the US prohibit young people from driving during late evening or early morning hours (curfew laws). Comparisons of rates between these and otherwise similar states suggest that these regulations are effective, and in addition, delay the age at which drivers obtain or seek to obtain driving licences. ${ }^{81-84}$

\section{Engineering}

Measures to protect young vehicle occupants by engineering can be subdivided into those involving the environment, such as road humps, and those involving the vehicle, such as safety inspections, or fitting airbags.

There have been numerous environmental measures that have reduced rates but none are specific to the $15-24$ age group.$^{85}$ The generally positive effects of area wide environmental schemes in five urban safety projects are reviewed in detail elsewhere. ${ }^{16}$ All areas showed some reduction in casualties, ${ }^{86}$ particularly in child cyclists and motorcyclists - a result also noted in the Netherlands. ${ }^{87}$

With regard to vehicle engineering, the effectiveness of vehicle inspections might be an important issue for younger drivers and passengers who often drive older cars. However, the only trial we identified showed conclusively that, when random roadside testing was present, the addition of periodic testing made no difference to the accident rate. ${ }^{88}$

\section{Home and work}

We identified no studies specifically relating to 15-24 year olds in domestic settings. Studies demonstrating the effectiveness of smoke detector programmes are clearly relevant to this age group, however. ${ }^{89} 90$

Our review identified only two examples of intervention studies aimed specifically at young people at work, although in both, unfortunately, evaluation was inconclusive. ${ }^{3891}$

\section{Community based approaches}

Essential elements of a community intervention programme would include involvement in the local community's network, the inclusion of vulnerable groups, and several years for the programme to run. ${ }^{92}$ Examples include the European Healthy Cities programmes, a Safe Block project in the USA, ${ }^{93}$ a Safety Round project in Sweden, ${ }^{94}$ the Corkerhill project in Glasgow, ${ }^{95}$ and the campaign against home accidents in Norway. ${ }^{96}$ Small scale projects include smoke detector programmes aimed at high risk populations in cities in the USA ${ }^{89} 90$ Compelling cases have been made for such community oriented programmes ${ }^{92} 95$ mainly because of the 'lack of fit' between most other health promoting strategies and the context in which those targeted live their lives.

Our search identified two community based interventions that reported results of special relevance to the young. The first is a Swedish programme, ${ }^{98}$ comparing injury rates in two rural areas and involving the cooperation of local authorites, organisations, and individual citizens. The interventions included changes to the physical environment as well as information, education, and supervision. While there are some methodological difficulties in this study, it is unique in specifically reporting outcomes in the 15-24 year old age group. A fall in injury rates in both home and work settings followed the intervention, although for workplace accidents the fall was not as great among the young as in older age groups.

The second is a non-randomised cohort study, the 'Safe Block' project, involving a poor 
urban community in Philadelphia. ${ }^{93}$ This found that an intervention consisting of home modification, inspection, and education led to a significant improvement in instituting preventive measures and greater knowledge in the intervention group, but it failed to measure injury rates.

The encouraging results from community based approaches, with their inclusion of all age groups and a wide range of outcomes, suggests that a multiagency strategy combining a variety of interventions may be a promising approach to prevention. Evaluation is not straightforward in terms of traditional epidemiological study design, however, because these 'interventions' are often multifaceted and deliberately not restricted to a defined or randomly selected population. Thus community based interventions are not usually amenable to randomised controlled trials. The result is that, while many such projects are established, few are formally evaluated and where evaluation does occur it is likely to be only in qualitative terms. Although a qualitative study is likely to help understand why something does or does not work, even a 'less than rigorous' attempt to measure some of the quantitative outcomes is likely to be better than none at all. Accordingly, whenever community based approaches to accident prevention are being planned, the opportunity to conduct some kind of quantitative evaluation should not be missed.

\section{Sport and leisure}

Many studies of particular sports suggest measures necessary to reduce the incidence and severity of injuries..$^{99-101}$ Our search revealed relatively few studies relating specifically to young people, however, but because one half of all sports related injuries occur in the age group 16-25 years, ${ }^{102}$ all the interventions yielded by the search, other than those aimed specifically at children or the elderly, were considered.

\section{RULE CHANGES}

Rule changes in some sports have been effective in reducing certain types of injury. Facial and oral injuries were reduced by more than $50 \%$ in the period after a rule change in 1962 mandating the wearing of face protectors and mouthguards in American football. ${ }^{103}$ Similarly, the introduction of mandatory face protectors in ice hockey in Québec was followed by dramatic decreases in all facial injuries. ${ }^{104}$

Decreases in the number of American footballers suffering permanent quadriplegia were reported after changes were made to the rules governing tackling and spearing, and similarly in rugby union players in the wake of changes to the rules associated with the tackle, scrum, and maul. ${ }^{105-109}$ These results may in part be due to decreases in the numbers exposed to risk.

\section{PROTECTIVE DEVICES}

Simple protective devices may also be effective. Injury risk in horseriding differs from that in other popular sports in that the risk of sustaining any injury is low but if an injury does occur it is likely to be serious. The serious nature of reported head injuries ${ }^{109}$ suggests strongly that helmets should be worn, but horseriding helmets probably provide a lower level of protection than cycle and motorcycle helmets. ${ }^{110}$

Custom made mouthguards can prevent or reduce the severity of injuries to the lips, mouth, and teeth. ${ }^{11112}$ Evidence from laboratory trials suggests that by altering oral structures, mouthguards may provide protection against concussion in players prone to that kind of injury. ${ }^{113114}$ However, one study found no statistically significant differences in oral injuries between wearers and non-wearers of mouthguards. ${ }^{115}$ Although substantial reductions in oral injuries followed the introduction of mandatory mouthguards and face protectors in American football, as both devices were introduced at the same time, it is not possible to isolate the specific contribution of each.

In contact sports, like boxing and rugby, the use of mouthguards is advocated but studies to test their effectiveness suffer from poor compliance rates. ${ }^{116}$ Reported reasons for noncompliance include attitude, cost, physical discomfort, functional impairment of speech and breathing, difficulties with retention, and durability. Despite calls for the use of mouthguards in children's and adolescent rugby, successful implementation appears unlikely until issues of efficacy, design, and cost are resolved.

Evidence for the efficacy of knee braces in American football is modest, and there are conflicting results with the protective effects demonstrated in some studies being associated with player position. ${ }^{116-121}$ There is also evidence to demonstrate that belts are effective in preventing injuries to the back among weightlifters. $^{122}$

Injuries to the ankle account for approximately $16 \%$ of all new sports injuries in adults. Prophylactic taping may be effective in primary prevention of injury, ${ }^{123} 124$ and enhanced by the use of high top shoes. ${ }^{125}$

Eye injuries represent $0.2 \%$ of all sports related injuries and thus do not constitute an area where major public health gains can be expected. ${ }^{102}$ Nevertheless, serious eye injuries have been reported in squash, ${ }^{126}$ cricket, ${ }^{127}$ badminton, ${ }^{128}$ and in players of other high risk activities who wear prescription lenses or streetwear spectacles. ${ }^{129}$ Face protectors and guards can eliminate most injuries to the face, including eyes, and there is good evidence that eye protectors meeting specified standards prevent injury. Eye protectors are prohibited in two activities which carry high risk of eye injury: boxing and karate.

Collisions with 'the furniture' of the area of play are responsible for approximately $10 \%$ of all sports injuries. ${ }^{102}$ Accordingly, modifications to the sports environment can result in dramatic reductions in the number of injuries, demonstrated clearly by US studies of modified 'breakaway' bases used in baseball and softball. ${ }^{130-132}$ 
SPORTS EDUCATION

Studies of the effectiveness of a national mass media health promotion campaign targeted at young people $\mathrm{e}^{133}$ and a controlled trial of a sports injury prevention programme specially designed for schools ${ }^{134}$ showed improvements in knowledge and attitude to sports injuries but no effect on injury rates. Similarly, a multiagency collaboration involving manufacturers and horseriding clubs, and health promotion publicity about the risks of head injury, was successful in raising awareness and increasing sales of horseriding helmets. Unfortunately the impact on helmet use and head injury severity was not reported. ${ }^{135}$

A randomised controlled trial of a standardised package of warm-up and cool down exercises in recreational runners influenced knowledge and attitudes but had no effect on injury rates. ${ }^{136137}$ More encouraging were results from a study of elite Swedish soccer players, which involved a programme of standardised warm-up, ankle taping, particular shoe design, leg guards, and controlled rehabilitation. When administered by medical personnel, the programme reduced injuries by $75 \%$. This fell to $50 \%$ when supervised by the coaches. ${ }^{138}$

\section{Conclusions}

Few interventions to reduce injury in adolescents have been rigorously evaluated using good quality randomised controlled trials, and where such evidence is available, fewer have been shown to be definitely worthwhile. The most effective measures appear to be legislative and regulatory controls in road, sport, and workplace settings, although in some cases this may be the result of discouraging an activity, rather than making it safer. Environmental engineering measures on the road and in sports are also effective in reducing injury in all age groups and at relatively low cost. While the results reported from community based approaches are encouraging, there is little evidence that purely educational measures reduce injury rates in the short term.

Much injury research uses outcome measures that may not translate into injury rates when a measure is implemented. A good example is the available evidence on the effectiveness of daytime motorcycle headlamp use. Although car drivers colliding with motorcycles frequently report that they 'didn't see' the other road user, and surrogate field tests show that daytime headlamp use improved conspicuity, comparative studies of rates in US states with and without daytime motorcycle headlamp regulations offer no evidence of actual benefit.

This review has identified a small number of interventions that should be implemented on a widespread basis immediately, and that would reduce injury rates. For the most part, though, it is clear that there is still a long way to go before we can confidently say what works in preventing accidental injury to 15-24 year olds.

This work was funded by the UK Department of Health, but the views expressed are those of the author alone.
1 Office of Population Censuses and Surveys. Injuries and poisonings 1991 data. London: HMSO, 1992

2 Office of Population Censuses and Surveys. Fatal accidents occurring during sporting and leisure activities. OPCS Monitors Series DH4. London: OPCS, data published annually for 1984-91.

3 Department of Health. The health of the nation. London: HMSO, 1993.

4 Stevens A, Raftery J. Health care needs assessment. Vol 1. Oxford: Radcliffe Medical Press, 1994: 24.

5 Waters EA. Should pedal cyclists wear helmets? A comparison of head injuries sustained by pedal cyclists and motorcyclists in road traffic accidents. Injury 1986; 17: 372-5.

6 Simpson AHRW. Head injuries, helmets, cycle lanes, and cyclists. $B M F$ 1988; 296: 1161-2.

7 Wasserman RC, Waller JA, Monty MJ, Emery AB, Robinson DR. Bicyclists, helmets and head injuries: a riderbased study of helmet use and effectiveness. Am $\mathfrak{f}$ Public Health 1988; 78: 1220-1.

8 Thompson RS, Rivara FP, Thompson DC. A case-control study of the effectiveness of bicycle safety helmets. $N$ Engl f Med 1989; 320: 1361-7.

9 Thompson DC, Thompson RS, Rivara FP, Wolf ME. A case-control study of the effectiveness of bicycle safety helmets in preventing facial injury. Am $\mathcal{F}$ Public Health 1990; 80: $1471-4$.

10 Wasserman RC, Buccini RV. Helmet protection from head injuries among recreational bicyclists. Am $\mathcal{F}$ Sports $\mathrm{Med}$ 1990; 18: 96-7.

11 Spaite DW, Murphy M, Criss EA, Valenzuela TD, Meislin HW. A prospective analysis of injury severity amon helmeted and nonhelmeted bicyclists involved in collisions with motor vehicles. $f$ Trauma 1991 ; 31: 1510-6.

12 McDermott FT, Lane JC, Brazenor GA, Debney EA. The effectiveness of bicyclist helmets: a study of 1710 casualties. F Trauma 1993; 34: 834-45.

13 McDermott F, Lane J. Protection afforded by cycle helmets [letter]. $B M F$ 1994; 309: 877.

14 Maimaris C, Summers CL, Browning C, Palmer CR Injury patterns in cyclists attending an accident and emergency department: a comparison of helmet wearers and non-wearers. $B M \mathcal{F}$ 1994; 308: 1537-40.

15 Dorsch MM, Woodward AJ, Somers RL. Do bicycle safety helmets reduce severity of head injury in real crashes? Accid Anal Prev 1987; 19: 183-90.

16 Jarvis S, Towner E, Dowswell T. Reducing childhood accidents. The effectiveness of health promotion intervenaccidents. The effectiveness of health promotion interventions: a review of research methodologies. Newcaste upon Authority, 1994.

17 Vulcan AP, Cameron MH, Heiman L. Evaluation of mandatory bicycle helmet use in Victoria, Australia. Melbourne, Victoria, Australia: Monash University Acciden Research Centre, 1992.

18 Cote TR, Sacks JJ, Lambert-Huber DA, et al. Bicycle helmet use among Maryland children: effect of legislation and education. Pediatrics 1992; 89: 1216-20.

19 Dannenburg AL, Gielen AC, Beilenson PL, Wilson MH Joffe A. Bicycle helmet laws and educational campaigns: an evaluation of strategies to increase children's helmet use. Am $\mathcal{F}$ Public Health 1993; 83: 667-74.

20 Evans L. Cycle helmets and the law. Lancet 1994; 308: $1521-2$.

21 Lane JC, McDermott FT. Effectiveness of cyclist helmets. Lancet 1994; 344: 965.

22 Graitcer PL, Kellerman AL, Christoffel T. A review of educational and legislative strategies to promote bicycle helmets. Injury Prevention 1995; 1: $122-9$.

23 Muller A. Evaluation of the costs and benefits of motorcycle helmet laws. Am $\mathcal{f}$ Public Health 1980; 70: 586-92.

24 Watson GS, Zador PL, Wilks A. Helmet use, helmet use laws and motorcyclist fatalities. Am f Public Health 1981 71: $297-300$

25 Somers RL. On the cost of repealing motorcycle helme laws. Am f Public Health 1983; 73: 1216.

26 Weisbuch JB. The prevention of injury from motorcycle use: epidemiologic success, legislative failure. Accid Anal Prev 1987; 19: 21-8.

27 Chenier TC, Evans L. Motorcyclist fatalities and the repeal of mandatory helmet wearing laws. Accid Anal Prev 1987; 19: $133-9$.

28 Watts GR. Evaluation of conspicuity aids for pedal cyclists. Laboratory report 1103. Crowthorne, Berks: Vehicles Safety Division, Transport and Road Research Laboratory, 1984

29 Olson PL, Halstead-Nussioch R, Sivak M. The effect of improvement in motorcycle/motorcylcist conspicuity on driver behavior. Hum Factors 1981; 23: 237-48.

30 Donne GL, Fulton EJ. The evaluation of aids to the daytime conspicuity of motorcycles. Laboratory report 1137 . Crowthorne, Berks: Vehicles Safety Division, Transport and Road Research Laboratory, 1985.

31 Muller A. An evaluation of the effectiveness of motorcycle daytime headlight laws. Am $\mathcal{f}$ Public Health 1982; 72 $1136-41$.

32 Muller A. Daytime headlight operation and motorcyclis fatalities. Accid Anal Prev 1984; 16: 1-18.

33 Mortimer RG. Evaluation of the motorcycle rider course. Accid Anal Prev 1984; 16: 63-70.

34 Mortimer RG. A further evaluation of the motorcycle ride course. Fournal of Safety Research 1988; 19: 187-96.

35 Raymond S, Tatum S. An evaluation of the effectiveness of the RAC/ACU motorcycle training scheme - final report Salford: Road Safety Research Unit, Department of Civil Engineering, University of Salford, 1977. 
36 Jonah BA, Dawson NE. Validation of the motorcycle operator skill test. Accid Anal Prev 1979; 11: 163-71.

37 Jonah BA, Dawson NE, Bragg BWE. Are formally trained motorcyclists safer? Accid Anal Prev 1982; 14: 247-55.

38 Adams A, Collingwood V. Evaluation of the 1982 Australia post motorcycle rider training scheme. Rosebery, New South Wales, Australia: Traffic Accident Research Unit, Traffic Authority of New South Wales, 1985.

39 McDavid JC, Lohrmann BA, Lohrmann G. Does motorcycle training reduce accidents? Evidence from a longitudinal quasi-experimental study. Fournal of Safety Research 1989; 20: 61-72.

40 Laberge-Nadeau C, Maag U, Bourbeau R. The effects of age and experience on accidents with injuries: should the licensing age be raised? Accid Anal Prev 1992; 24: 107-16.

41 Raymond S, Jolly KW, Risk AW, Shaoul JE. An evaluation of the effectiveness of driver traffic education in reducing road accidents among adolescents. Salford: Department of Civil Engineering, University of Salford, 1973.

42 Harrington DM. The young driver follow-up study: an evaluation of the role of human factors in the first four years of driving. Accid Anal Prev 1972; 4: 191-240.

43 Naatanen R, Summala H. Road-user behavior and traffic accidents. Amsterdam: North-Holland Publishing Company, 1976.

44 Thompson M, O'Reilly D. The young driver project. County Road Safety Officers Association South East Group. Crowthorne, Berks: Transport and Road Research Laboratory, 1993.

45 Lund AK, Williams AF, Zador P. High school driver education: further evaluation of the Dekalb County study. Accid Anal Prev 1986; 18: 349-58.

46 Struckman-Johnson DL, Lund AK, Williams AF, Osborne DW. Comparative effects of driver improvement programs on crashes and violations. Accid Anal Prev 1989; 21: 203-15.

47 Mann RE, Vingilis ER, Leigh G, Anglin L, Blefgen H. School-based programmes for the prevention of drinking and driving; issues and results. Accid Anal Prev 1986; 18: and driving;.

48 Redman S, Sanson-Fisher R, Cockburn J. Rehabilitation programs for drink drivers: a critical appraisal. Comprograms for drink drivers: a critical app
munity Health Studies 1988; 12: 418-27.

49 Frank RG, Bouman DE. A preliminary study of a traumatic injury prevention program. Psychology and Health 1992(ii); 6: 129-40.

50 Lechman BC, Bronwich EB. Evaluation of an education program for spinal cord injury prevention: some preliminary findings. Spinal
Systems) 1991; 3: 27-34.

51 Mackie AM, Valentine SD. Effectiveness of different 'appeals' in road safety propaganda. Laboratory report 669. Crowthorne, Berks: Transport and Road Research Laboratory, Department of the Environment, 1975.

52 Robertson LS, Kelly AB, O'Neill B, Wixom CW, Eiswirth RS, Haddon Jr W. A controlled study of the effect of television messages on safety belt use. Am ₹ Public Health 1974; 64: 1071-80.

53 Roberts M, Fanurik D. Rewarding elementary schoolchildren for their use of safety belts. Health Psychol 1986; 5: 185-96.

54 Roberts MC, Fanurik D, Wilson DR. A community program to reward children's use of seat belts. Am $\mathcal{F}$ Community Psychol 1988; 16: 395-407.

55 Department of Transport. Road accidents Great Britain 1993. The casualty report. London: HMSO, July 1994.

56 Nicholl JP, Freeman MR, Williams BT. Effects of subsidising bus travel. $\mathcal{f}$ Epidemiol Community Health 1987; 41: $50-4$.

57 Allsop R. Fares and road casualties in London. Report to the Transport and Development Department of Greater London Council, August. University College, London: Transport Studies Group, 1981.

58 McKenna FP. Drivers' perception of risk. Proceedings of conference organised by the Parliamentary Advisory Council for Transport Safety (PACTS). London: St Thomas' cil for Transport

59 Delhomme $P$. Comparing one's driving with others': assessment of abilities and frequency of offenses. Evidence for a superior conformity of self-bias? Accid Anal Prev 1991; 23: 493-508.

60 DeJoy D. An examination of gender differences in traffic accident risk perception. Accid Anal Prev 1992; 24: 237-46.

61 Martens $\mathrm{CH}$, Ross L, Mundt J. Young drivers' evaluation of driving impairment due to alcohol. Accid Anal Prev 1991; 23: 67-76.

62 Manstead ASR. Social phychological aspects of driver behaviour. Proceedings of a conference organised by the
Parliamentary Advisory Council for Transport Safety (PACTS). London: St Thomas' Hospital, 1991.

63 Farrow JA. Young driver risk taking: a description of dangerous driving situations among 16 to 19 year old drivers. Int $\mathcal{f}$ Addict 1987; 22: 1255-7.

64 Rolls G, Ingham R. Safe and unsafe - a comparative study of younger male drivers. Basingstoke, Hants: AA Foundof younger male drivers. Basingstoke, Han

65 Schaps E, DiBartolo R, Moskowitz J, Palley CS, Churgin S. A review of 127 drug abuse prevention program S. A review of 127 drug abuse prevention program
evaluations. Fournal of Drug Issues 1981; winter: 17-43.

66 Pentz MA, Dwyer JH, MacKinnon DP, et al. A multicommunity trial for primary prevention of adolescent drug abuse: effects on drug use prevalence. $\mathcal{F} A M A 1989 ; 261$ : 3259-66.
67 Roberston LS. Crash involvement of teenaged drivers when driver education is eliminated from high school. $\mathrm{Am}$ f Public Health 1980; 70: 599-603.

68 Levy DT. The effects of driving age, driver education, and curfew laws on traffic fatalities of 15-17 year olds. Risk Anal 1988; 4: 569-74.

69 Levy DT. Youth and traffic safety: the effects of driving age, experience, and education. Accid Anal Prev 1990; 22 327-34.

70 Williams AF, Karpf S, Zador PL. Variations in minimum licensing age and fatal motor vehicle crashes. Am $\mathcal{F}$ Public Health 1983; 73: 1401-3.

71 Preusser DF. Delaying teenage licensure. Alcohol, Drug and Driving 1988; 4: 283-95.

72 Asch P, Levy DT. Does the minimum drinking age affect traffic fatalities? fournal of Policy Analysis and Management 1987; 6: 180-92.

73 Jones NE, Pieper CF, Robertson LS. The effect of legal drinking age on fatal injuries of adolescents and young adults. Am F Public Health 1992; 82: 112-4.

74 MacKinnon DP, Woodward JA. The impact of raising the minimum drinking age on driver fatalities. Int $\mathcal{f}$ Addict 1986; 21: 1331-8.

75 Robertson LS. Blood alcohol in fatally injured drivers and the minimum legal drinking age. $\mathcal{f}$ Health Polit Policy Law 1989; 14: 817-25.

76 Hingson $R$, Merrigan D, Heeren T. Effects of Massachusetts raising its legal drinking age from 18 to 20 on deaths from teenage homicide, suicide and nontraffic accidents. Pediatr Clin North Am 1985; 32: 221-32.

77 Williams AF, Zador PL, Harris SS, Karpf RS. The effect of raising the legal minimum drinking age on involvement in fatal crashes. Fournal of Legal Studies 1983; XII: 169-79.

78 Broughton J, Stark DC. The effect of the 1983 changes to the law relating to drink/driving. Research report 89 . Crowthorne, Berks: Road Safety Division, Safety and Transportation Department, Transport and Road Research Laboratory, 1986.

79 Dunbar JA, Penttila A, Pikkarainen J. Drinking and driving: success of random breath testing in Finland. driving: success of rand.

80 Vingilis E, Salutin L. A prevention programme for drinking driving. Accid Anal Prev 1980; 12: 267-74.

81 Levy DT. The effects of driving age, driver education, and curfew laws on traffic fatalities of 15-17 year olds. Risk Anal 1988; 4: 569-74

82 Levy DT. Youth and traffic safety: the effects of driving age, experience, and education. Accid Anal Prev 1990; 22: 327-34.

83 Preusser DF, Williams AF, Zador PL, Blomberg RD. The effect of curfew laws on motor vehicle crashes. Law and Policy 1984; 6: 115-28.

84 Preusser DF, Williams AF, Lund AK, Zador PL. City curfew ordinances and teenage motor vehicle injury. Accid Anal Prev 1990; 22: 391-7.

85 Sabey B. Road safety and value for money. Supplementary report 581. Crowthorne, Berks: Accident Investigation Division Safety Division, Transport and Road Research Laboratory, 1980.

86 Mackie AM, Ward HA, Walker RT. Urban safety project 3. Overall evaluation of area wide schemes. Research repor 263. Crowthorne, Berks: Traffic Safety Division, Transport and Road Research Laboratory, 1990.

87 Janssen STMC. Road safety in urban districts. Traffic Engineering and Control 1991; 292-6.

88 Fosser S. An experimental evaluation of the effects of periodic motor vehicle inspection on accident rates. Accid Anal Prev 1992; 24: 599-612.

89 Gorman RL, Charney E, Holtzman NA, Roberts KB. A successful city-wide smoker detector giveaway program Pediatrics 1985; 75: 14-8.

90 Hammond J, Varas R. Co-ordinated strategies in burn prevention programs; a case study. $\mathcal{f}$ Burn Care Rehabil 1990; 11: 376-8.

91 Corcoran H. Safety for youth in agriculture. Safety Standards 1967; 16: 1-3.

92 Popay J, Young A. Reducing accidental death and injury in children. A report produced for the North West Regional Health Authority Public Health Working Group on Child Accidents. Manchester: NWRHA 1994.

93 Schwarz DF, Grisso JA, Miles C, Homes JH, Sutton RL. An injury prevention program in an urban AfricanAmerican community. Am $\mathcal{f}$ Public Health 1993; 83: 675-80.

94 Bjaras G, Danielsson K, Schelp L, Sjoberg D, Skjonberg G. Safety rounds in public environments: experience of new tool for prevention of accidental injuries. Accid Anal Prev 1990; 22: 223-8.

95 Roberts H, Smith S, Bryce C. Prevention in better. Sociology of Health and Illness 1993; 15: 447-63.

96 Thuen F, Maeland JG. Accident prevention activities in the Norwegian municipalities: the local response to a

97 Schelp L. The role of organizations in community ticipation - prevention of accidental injuries in a rural ticipation - prevention of accidental injuries in a rura
Swedish municipality. Soc Sci Med 1988; 11: 1087-93.

98 Schelp L. Community intervention and changes in accident pattern in a rural Swedish municipality. Health Promotion pattern in a rural

99 Mackie SJ, Taunton JE. Injuries in female gymnasts. Trends suggest prevention tactics. Physician and Sports Medicine 1994; 22: 40-5.

100 Fyfe IS, Guion AJ. Accident prevention in skateboarding. fournal of Sports Medicine 1979; 19: 265-6. 
14 year review. 7 Trauma 1989; 29: $245-7$

102 Nicholl JP, Coleman P, Williams BT. Injuries in sport and exercise. Main report. London: Sports Council, 1993.

103 Bureau of Dental Health Education. Mouth protectors: 11 years later. $\mathcal{A}$ Am Dent Assoc 1973; 86: 1365-7.

104 Regnier G, Goulet C. The effects of a governmental regulation requiring the use of a full-face protector for adult recreational hockey players. Proceedings of The Second World Conference on Injury Control. Atlanta, Georgia, 20-23 May 1993.

105 Tori JS, Vegso JJ, Sennett B, Das M. The National football head and neck injury registry 14-year report on cervical quadriplegia 1971 through 1984 . $₹ A M A$ 1985; 254: 3439-43.

106 Burry HC, Calcinai CJ. The need to make rugby safer. $B M F$ 1988; 296: 149-50.

107 Silver JR. Injuries of the spine sustained during rugby. $\mathrm{Br} \mathcal{F}$ Sports Med 1992; 26: 253-8.

108 Silver JR, Stewart D. The prevention of spinal injuries in rugby football. Paraplegia $1994 ; 32: 442-3$

109 Ingemarson $H$, Grevsten S, Thoren L. Lethal horse-riding ingemarson H, Grevsten S, Thoren L.

110 Mills NJ, Whitlock MD. Performance of horse-riding helmets in frontal and side impacts. Injury 1989; 20: 189-92.

111 Wet de FA. The prevention of orofacial injuries in the adolescent. Int Dent $\mathcal{F} 1981$; 31: 313-9.

112 Turner CH. Mouth protectors. Br Dent $₹$ 1977; 143: 82-6.

113 Stenger JM, Lawson EA, Wright JM, Ricketts J. Mouthguards: protection against shock to head, neck and teeth. $f$ Am Dent Assoc 1964; 69; 273-81.

114 Hickey JC, Morris AL, Carison LD, Seward TE. The relation of mouth protectors to cranial pressure and deformation. F Am Dent Assoc 1974; 73: 735-40.

115 Blignaut JB, Carstens IL, Lombard CJ. Injuries sustained in rugby by wearers and non-wearers of mouthguards. $\mathrm{Br}$ in rugby by wearers and non-we

116 Morton JG, Burton JF. An evaluation of the effectiveness of mouthguards in high-school rugby players. NZ Dent $\mathcal{J}$ 1979; 75: $151-3$.

117 Albright JP, Powell JW, Smith W, et al. Medial collateral ligament knee sprains in college football. Effectiveness of

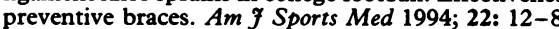

118 Schootman $M$, Mechelen van W. Efficacy of preventive knee braces in football: epidemiological assessment. Clinical fournal of Sport Medicine 1993; 3: 166-73.

119 Teitz CC, Hermanson BK, Kronmal RA, Diehr PH. Evaluation of the use of braces to prevent injury to the knee in collegiate football players. $\mathcal{F}$ Bone foint Surg Am 1987; 69: 2-9.

120 Sitler M, Ryan J, Hopkinson W, et al. The efficacy of a prophylactic knee brace to reduce knee injuries in football. A prospective, randomised

121 Brown TD, Hoeck van JE, Brand RA. Laboratory evaluation of prophylactic knee brace performance under dynamic valgus loading using a surrogate leg model. Clin Sports Med 1990; 9: 751-62.

122 Bourne ND, Reilly $\mathrm{T}$. Effect of a weightlifting belt on spinal shrinkage. Br $\mathcal{f}$ Sports Med 1991; 25: 209-11.

123 Yamamoto T, Kigawa A, Xu T. Effectiveness of functional ankle taping for judo athletes: a comparison between judo bandaging and taping. $\mathrm{Br} \mathcal{F}$ Sports Med 1993; 27: 110-2.

124 Firer P. Effectiveness of taping for the prevention of ankle ligament sprains. Br $\mathcal{F}$ Sports Med 1990; 24: 47-50.

125 Garrick JG, Requa RK. Role of external support in the prevention of ankle sprains. Medicine and Science in Sports 1973; 5: 200-3.

126 Bankes KJL. Squash rackets: a survey of eye injuries in England. $B M \mathcal{F}^{1985}$; 291: 1539-40.

127 Jones NP. One year of severe eye injuries in sport. Eye 1988; 2: 484-7.

$128 \mathrm{Kelly} \mathrm{SP}$. Serious eye injury in badminton players. $\mathrm{Br} \mathrm{F}$ Ophthalmol 1987; 71: 746-7.

129 Easterbrook $M$. Eye protection in racket sports: an update. Physician and Sports Medicine 1987; 15: 180-92.

130 Janda DH, Woitys EM, Hankin FM, Benedict ME. Softball sliding injuries. A prospective study comparing standard and modified bases. $\mathcal{F} A M A$ 1988; 259: 1848-50.

131 Janda DH, Wojtys EM, Hankin FM, Benedict ME, Hensinger RN. A three-phase analysis of the prevention of recreational software injuries. Am $\mathcal{J}$ Sport Med 1990; 18: $632-5$.

132 Janda DH, Maguire R, Mackesy D, Hawkins RJ, Fowler P, Boyd J. Sliding injuries in college and professional baseball. A prospective study comparing standard and breakaway bases. Clinical fournal of Sport Medicine 1993; 3: $78-81$.

133 Van Kernebeek E. Sports injuries, how to prevent them. A nationwide health education campaign in the Netherlands 1988-92. Evaluation report. Amsterdam: Dutch Institute of Sports and Health Consumer Safety Unit, November of Spor.

134 Backx FJG. Intervention strategy based on a model for behavior modification to reduce sports injuries. Sports injuries in youth. Janus Jongbloed Research Centrum, Rijksuniversiteit Utrecht: National Instituut voor de Sportgezondheidszorg, 1991: 65-78.

135 Condie C, Rivara FP, Bergman AB. Strategies of a successful campaign to promote the use of equestrian helmets. Public Health Rep 1993; 108: 121-6.

136 Van Mechelen $W$. The prevention of running injuries by warming-up, stretching exercise and cooling-down: an experimental study. Aetiology and prevention of running injuries. Amsterdam. Aetiology and prevention of running Gezondheid, 1992: 105-28.

137 Van Mechelen W, Hlobil H, Kemper HCG, Voorn WJ, Jongh HR. Prevention of running injuries by warm-up,
cool-down, and stretching exercises. Am $\mathcal{f}$ Sports Med 1993; 21: 711-9.

138 Ekstrand J, Gillquist J. Prevention of sports injuries in football players. Int $\mathcal{f}$ Sports Med 1984; suppl 5: 140-4.

\section{Most excellent E-codes}

A syndicated columnist in the US, Dave Berry, has written a whimsical piece calling attention to the Official Government Classification of Bad Medical Things That Could Happen on Your Vacation, also known as the International Classification of Diseases. $\mathrm{He}$ is especially intrigued by the following E-codes: E845, accident in spacecraft; E912, bean in nose; E966, beheaded by guillotine; E906.8, butted by animal; E915, hairball; E912, marble in nose; E906.8, pecked by bird; and E844, my greatest concern, sucked into jet aircraft. 